\title{
Testing, modelling and design of bolted joints - effect of size, structural properties, integrity and robustness
}

\author{
A. Kozlowski \\ Rzeszow University of Technology, Rzeszow, Poland \\ P. Kawecki \\ Civil Engineering Office Mostostal Co., Warsaw, Poland \\ D. Kukla \\ Inzynieria Rzeszow SA, Rzeszow, Poland \\ K. Ostrowski \\ MTA Engineering, Rzeszow, Poland
}

\begin{abstract}
Research activities aiming at understanding selected items of steel joints behavior in the persistent and accidental situation has been conducted at Rzeszow University of Technology. The following subjects were considered: the behavior of beam splices of beams in large size steel industrial structures and especially the assessment of safety to use the component method of EN 1993-1-8 to design such joints; the role of joints in assurance survival of steel-framed structures subjected to accidental loading, especially influence of joints geometrical and material properties on their behavior in column loss scenario; estimation of actual values of available rotation capacity of selected steel joints, to be used in robustness analysis of steel frames. An investigation was provided by experimental tests of bolted end-plate joints, advanced FEA with the use of validated models, and wide parametric studies. Results of the above-mentioned researches can find application in design practice.
\end{abstract}

\section{INTRODUCTION}

Joints, in the same range as members, have a decisive influence on steel structures' safety and economy. Proper shaping, design calculation, and appropriate details arrangement in technical drawings play an essential role in providing competitiveness, long-time exploitation, failure-free solution. During the last decade's very large experimental, theoretical, and fine element modeling researches were conducted to provide modern design tools to practitioners. Many of these findings were incorporated to design codes, as (EN 1993-1-8 2005). Despite this, still exist few gaps in regulation provisions. A few of them, which are the subject of research projects and doctoral dissertation conducted at Rzeszow University of Technology, are presented below. The following subjects will be described:

- behavior of joints in large-scale steel structures, i.e. influence of the size of the joints designed according to (EN 1993-1-8 2005) on the structure safety,

- behavior of steel-framed structures under exceptional loading condition (robustness) and the role of joint in counteraction against the progressive collapse of the structure,

- quantitative assessment of rotation capacity of joints, while in (EN 1993-1-8 2005) only qualitative rules are available. 


\section{BEHAVIOUR OF JOINTS IN LARGE-SCALE STEEL STRUCTURES}

The component method used in the standard (EN 1993-1-8 2005) has been developed for joints in framed building structures, where usually bolted end-plate connections are used, with two-three rows of bolts located in the vicinity of the tensioned flange of the beam (Figure 1a). The members of such frames were made of IPE sections with a height of not more than 400$450 \mathrm{~mm}$, very often of class 1 or 2 . Numerous experimental tests of such joints confirm the adequacy of the component method for such frame joints. In the case of higher beams, especially those with a plate welded girder cross-section $\left(h_{b}=1000-2000 \mathrm{~mm}\right)$, connected by endplate splices with many bolt rows (Figure 1b), the standard (EN 1993-1-8 2005) methods fail, especially with regard to the distribution of internal forces in individual bolt rows, when assessing the resistance (see 6.2.7.2 (EN 1993-1-8 2005)).

Calculations of the design moment resistance of joints with several bolt rows are performed according to the component method using the formula:

$$
M_{j, R d}=\sum h_{r} \cdot F_{t r, R d}
$$

where: $F_{t r, R d}$ - the effective design tension resistance of bolt row $r, h_{r}$ - the distance from bolt row $r$ to the center of compression, $r$ - the bolt row number.

Only limitation to including in formula (1) all bolt rows with their full resistance, is:

- $\mathrm{T}<\mathrm{C}$ and/or $\mathrm{S}$; the resistance of the tension zone must be smaller than the resistance of compression and/or shear zone, and

- linear reduction of bolt row resistance acc. to (2) when the effective design tension resistance $F_{t x, R d}$ of one of the previous bolt rows $x$ is greater than $1.9 F_{t, R d}$ :

$$
F_{t r, R d} \leq F_{t x, R d} h_{r} / h_{x}
$$

where $h_{x}$ - the distance from bolt row $x$ to the center of compression, $x_{i}$ - the bolt row farthest from the center of compression that has a design tension resistance greater than $1.9 F_{t, R d}$.

This calculation method has not been changed in the current update of the standard (EN 1993-1-8 2005).

Comparison of sizes of bolted end-plate joints used for hot-rolled member section, typical for building structures and, welded I girders used in industrial structures is shown in Figure 1.

Many doubts and questions, coming from designers, were raised, if component method as in code (EN 1993-1-8 2005) is appropriate (safe) for large-size structure joints? In the opinion of professional engineers and few researchers, the answer for this question is not, because:

- the component method presented in (EN 1993-1-8 2005) in relation to joints of high beams is not confirmed by an experimental test of such joints - only a few tests of large size joints $\left(h_{b}>1000 \mathrm{~mm}\right.$ ) were conducted (Morrison et al. 1985), (Borgsmiller et al.1995), (Ryan 1999), (Sumner 2003), (Katula 2009), (Jain 2015) but most of them with only 2 - 3 bolt rows below tension flange,

- steel beams of large height are designed as composed welded girders, very often of class 4 section for web, where the transmission of forces down from tensioned beam flange through the very thin web is very doubtful,

- distribution of forces in particular bolt rows along beam height is not in conformity with stress distribution in the beam section.

Research project (Kawecki 2021) has been conducted in Rzeszow University of Technology, as follows:

- experimental tests of four beam splices of beam $1000 \mathrm{~mm}$ and $1500 \mathrm{~mm}$ high (Kawecki \& Kozlowski 2020),

- creation of fine element method joint models, hierarchically validated, 
Figure 1. Comparison of size of end-plate bolted joints, for a) rolled sections, b) welded section.

- parametric study to investigate the influence of other factors, e.g. end-plate thickness, steel grade, stiffening of the joints,

- verification of component method (EN 1993-1-8 2005) by comparison its results to experimental tests and parametric study results,

- proposal to improve component method procedures to be safe for large size beam joints.

Experimental tests were conducted for the following joints, shown in Figure 2.

Tests were performed in the Laboratory of Building Structures at Rzeszow University of Technology. View and picture of test stand were presented in Figure 3.

The following quantities were measured during tests: the strains along the bolt axis, the strains in the tension flange of the beam and in the web near the bolts, the strain in the compression flange, the separation of the end plates, the mid-span deflection of the beam and under the jacks. More details of test results can be found in (Kawecki \& Kozlowski 2020). Only selected of them are presented below. The distribution of forces in each bolt, obtained during experiments on the basis of measurement of bolt strains by strain gauges are shown in Figure 4. From Figure 4 it is seen that the distribution of forces in the particular bolt rows is not equal on the beam height. Also the moment resistance of the joint $M_{j, R k}$ determined by the component method is much bigger than reached during experimental tests.

Table 1 presents the values of actual forces in each bolt row, obtained on the basis of measurements of strains in bolts during tests, obtained from FEA analysis with the use of validated FEM models and values calculated using the component method from code (EN 1993-1-8 2005).

Figure 5 shows the distribution of forces in individual bolt rows $F_{t, R k, i}$, calculated according to the component method (EN 1993-1-8 2005), experimental tests $F_{t, i}$, FEM calculation $F_{t, i, m e s}$ for connection W2-1, and for comparison FEM results taking into account end-plate of $14 \mathrm{~mm}$ thickness.

Results presented in Figure 5 and Table 1 for joint W2-1 (end-plate thickness $16 \mathrm{~mm}$ ) confirm the conclusion that the distribution of bolt forces calculated acc. to code (EN 1993-1-8 2005) is very far away from obtaining in experiment and FEA, especially in lower bolt rows. 
W2-1

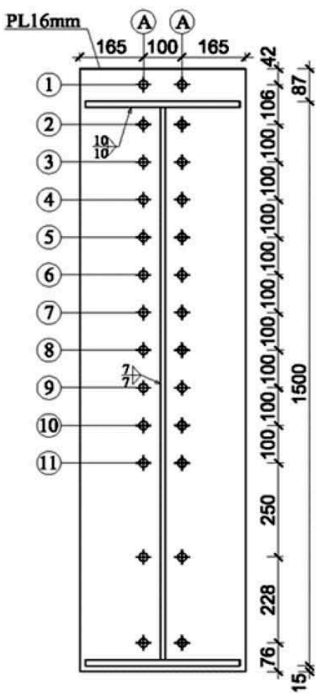

W1-1

PL16mm (C)B(A) (A) B) 45
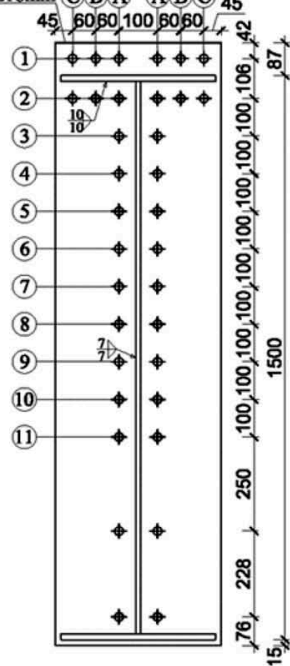

W3-1

PL20mm (B) (A) B

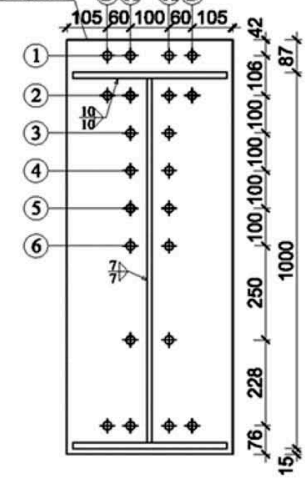

W3-2

PL16mm (B) A (A)

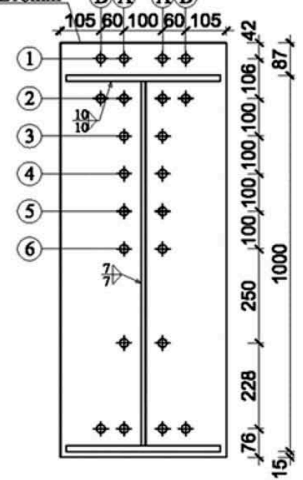

Figure 2. Experimentally tested joints.

Table 1. Comparison of actual bolt forces distribution obtained in tests and from FEA with values calculated acc. to the component method (EN 1993-1-8 2005).

\begin{tabular}{lllll}
\hline & & \multicolumn{2}{c}{$\mathrm{W} 2-1$} \\
\cline { 3 - 5 } & & $\mathrm{EXP}$ & $\mathrm{FEA}$ & $\mathrm{EC} 3$ \\
\cline { 3 - 5 } Bolt row number & $h_{i}[\mathrm{~m}]$ & $\mathrm{F}_{\mathrm{T}, \mathrm{i}}$ & $F_{T, i \text { mes }}$ & $\mathrm{F}_{\mathrm{T}, \mathrm{Rk}, \mathrm{i}}$ \\
\hline 1 & 1.537 & 362.8 & 417.2 & 380.1 \\
2 & 1.431 & 499.6 & 499.4 & 470.5 \\
3 & 1.331 & 281.2 & 246.6 & 344.4 \\
4 & 1.231 & 199.3 & 211.6 & 344.4 \\
5 & 1.131 & 174.1 & 176.8 & 344.4 \\
6 & 1.031 & 148.8 & 145.6 & 344.4 \\
7 & 0.931 & 104.6 & 117.2 & 344.4 \\
8 & 0.831 & 73.6 & 91.6 & 344.4 \\
9 & 0.731 & 67.1 & 68.6 & 0 \\
10 & 0.631 & 49.3 & 50 & $M_{j, R k}=3795$ \\
\hline 1 & 0.531 & 35.9 & 42.8 & 1.82 \\
\hline Moment resistance $[\mathrm{kNm}]$ & \multicolumn{5}{c}{$M_{B, k}=2090$} & $M_{B, k, m e s}=2124.5$ & 1.79 \\
\hline$M_{j, R k} / M_{B, k}$ & & & &
\end{tabular}

The same joint with the end-plate thickness $14 \mathrm{~mm}$ shows behavior much closer to test and FEA results. This is because T-stubs in joint with end-plate $14 \mathrm{~mm}$ show failure mode 1 while joints with end-plate $16 \mathrm{~mm}$ failure mode 2. That means that the component method as in code (EN 1993-1-8 2005) can be used for high beam splice only when T-stubs in all bolt rows show failure mode 1 . 
a)

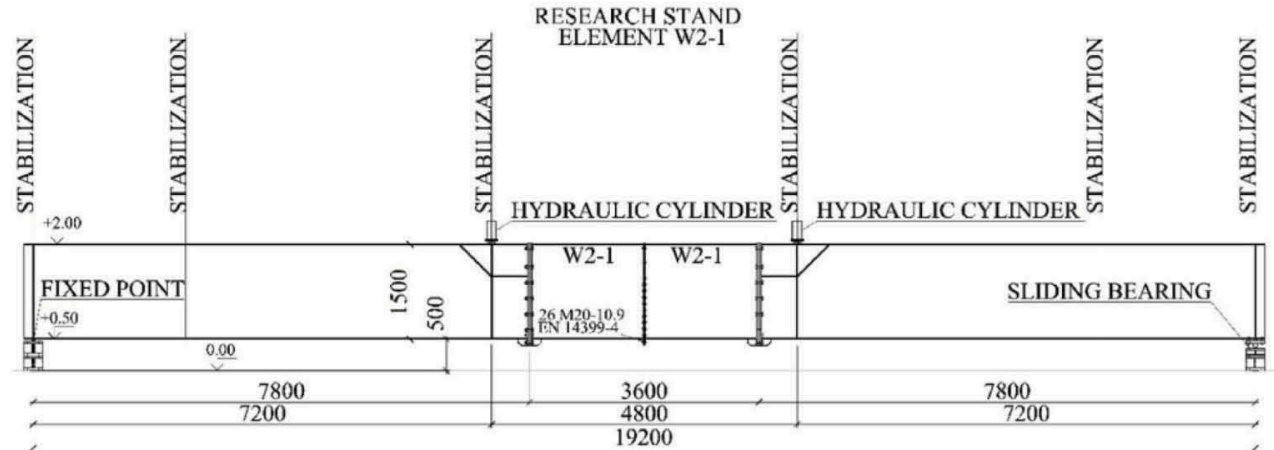

b)

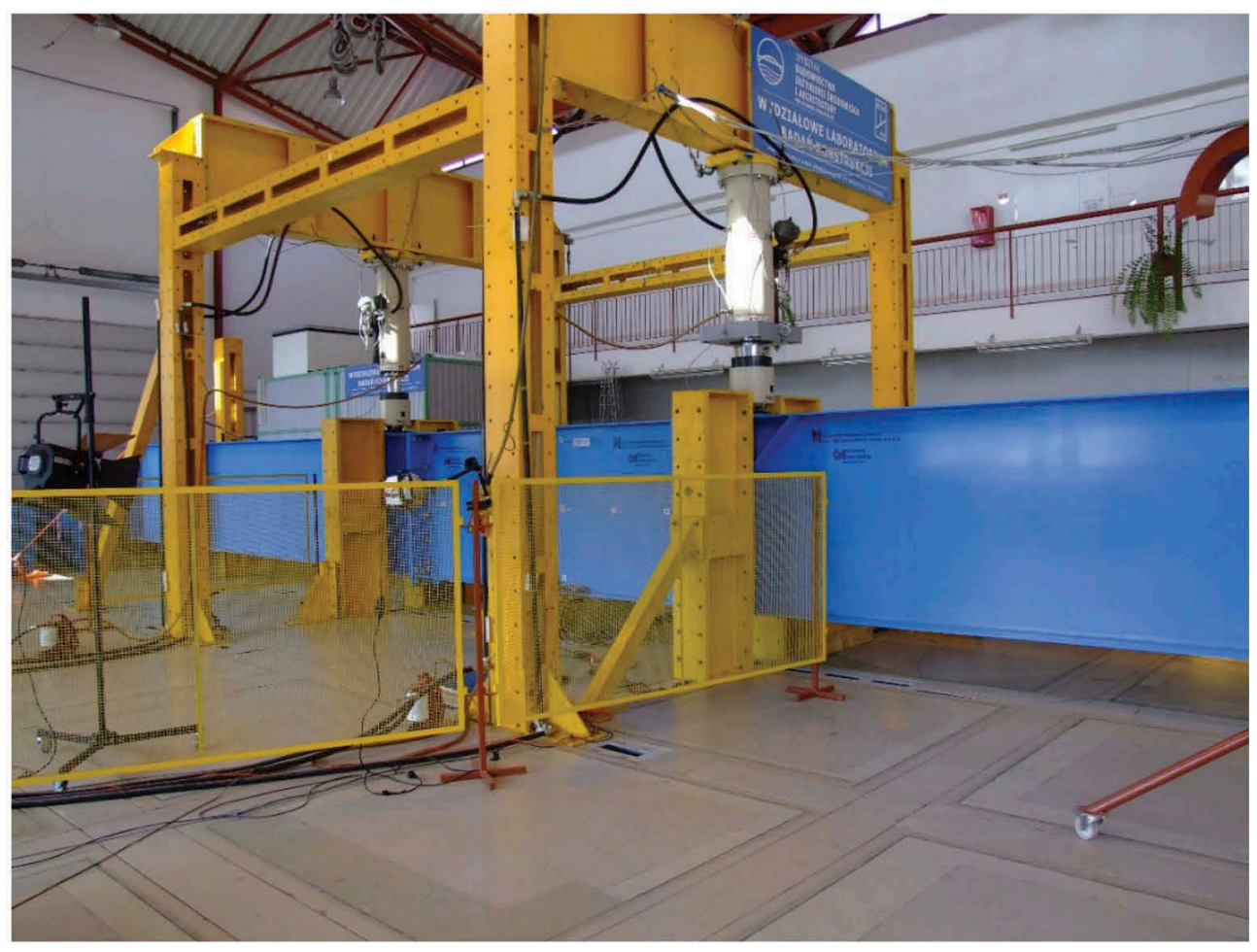

c)

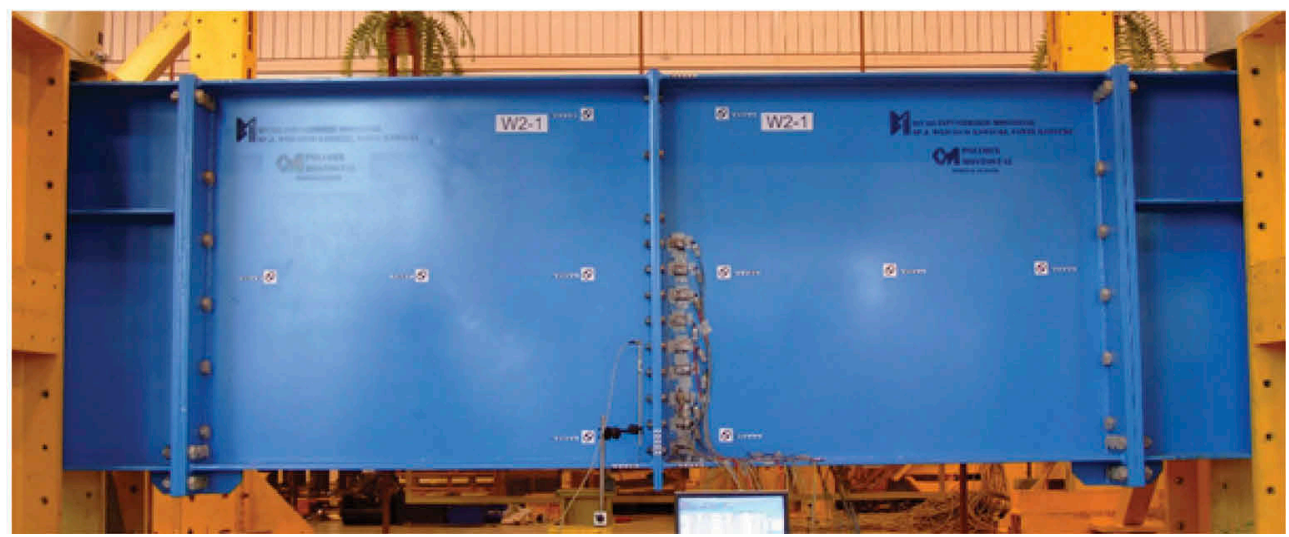

Figure 3. The test stand, a) scheme, b) general view, c) investigated specimen. 


\section{W2-1 Bolt Forces}

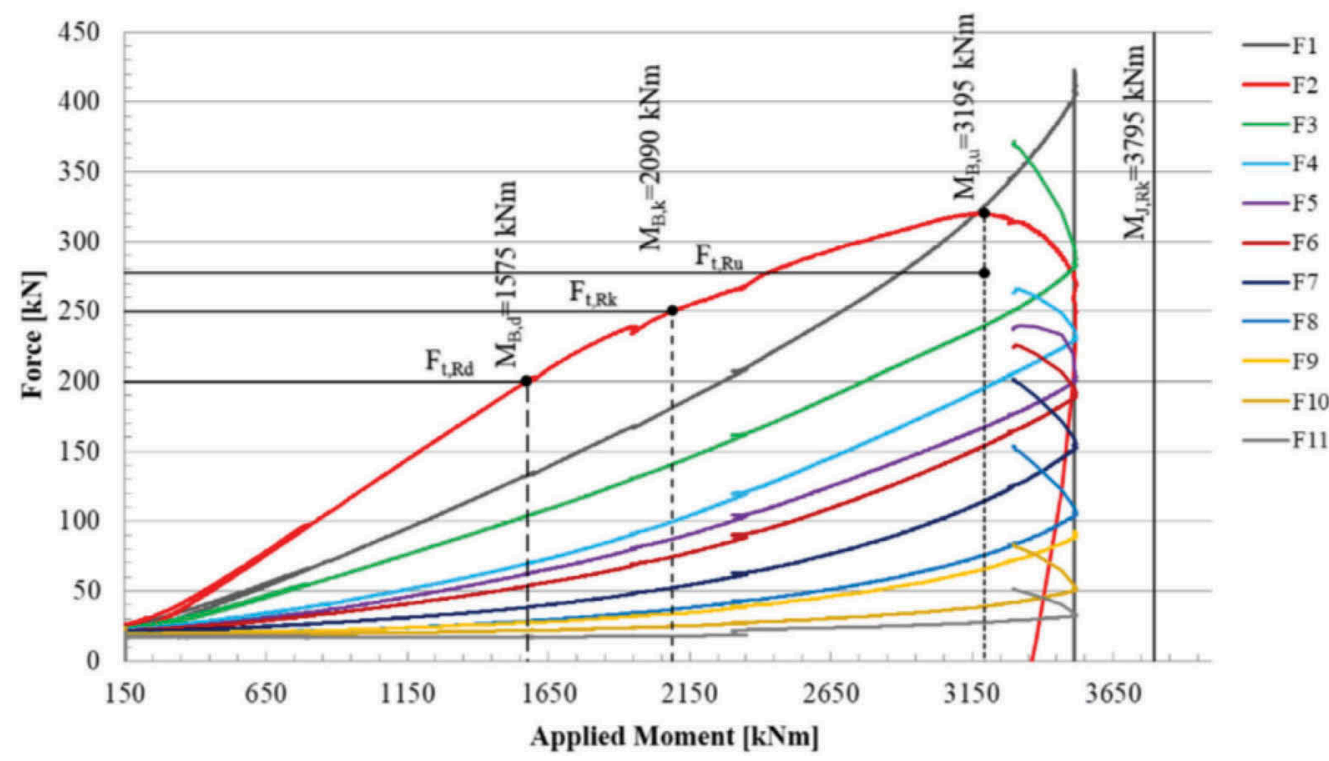

Figure 4. Moment vs. bolt-force distribution of specimen W2-1; $F_{i}$ forces in bolt row $i$, obtained from tests; notation of moments: $M_{B, d}$ when the design resistance of the bolt was reached; $M_{B, k}$ when the characteristic ultimate resistance of the bolt was reached; $M_{B, \mathrm{u}}$ when the ultimate resistance of the bolt was reached; $M_{j, R k}$ characteristic moment resistance obtained by component method (EN 1993-1-8 2005).
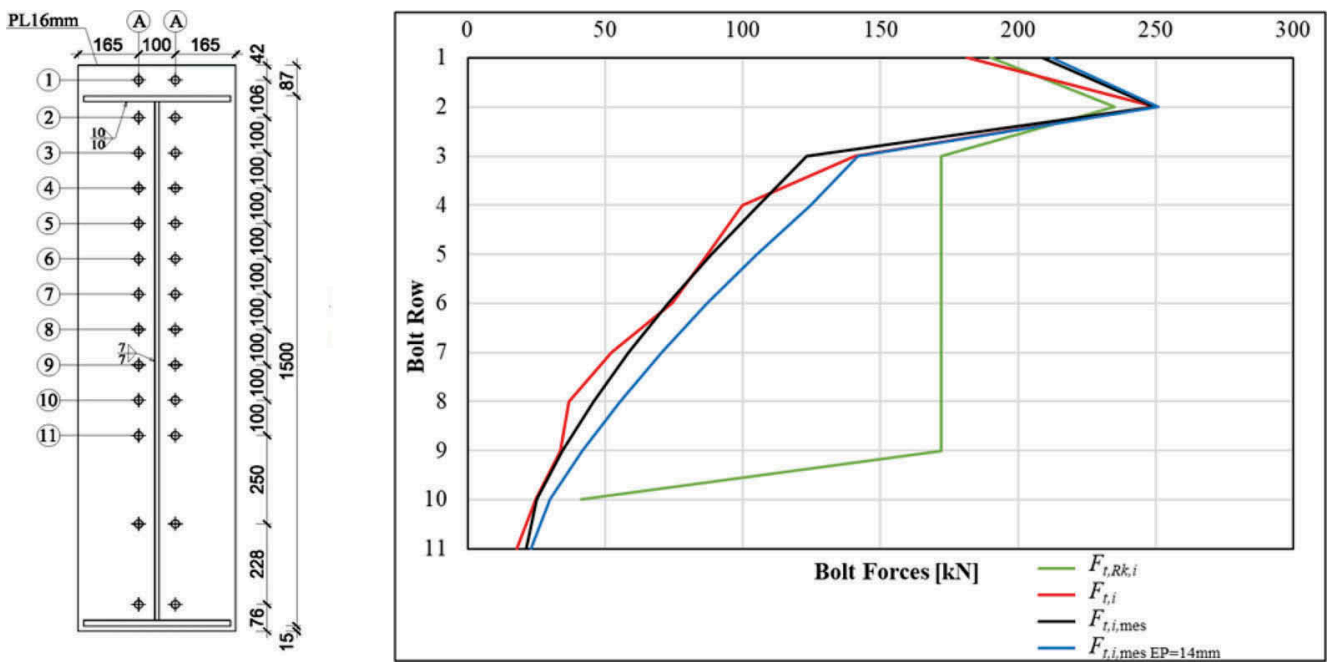

Figure 5. Distribution of forces in individual bolt rows according to component method (EN 1993-1-8 2005) $\left(F_{t, R k, i}\right)$, experimental tests $\left(F_{t, i}\right)$, FEM calculation $\left(F_{t, i, m e s}\right)$ for connection W2-1 and for comparison FEM results for end-plate of $14 \mathrm{~mm}$ thickness.

In Figure 6 results of FEM analysis with the use of validated joint model conducted for connection W2-1 (11 bolt rows) and in series, with 10, 9, 8, 7, 6, 5, 4, and 3 bolt rows were 


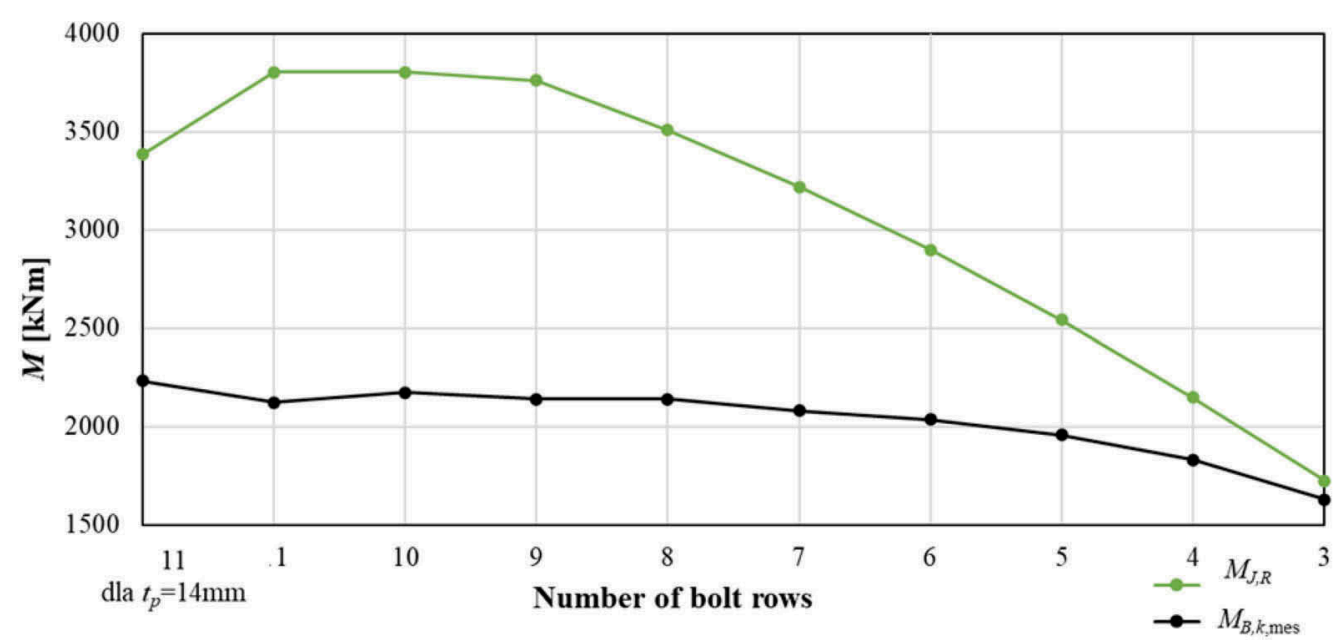

Figure 6. Characteristic moment capacity $M_{j, R k}$ according to EN 1993-1-8 (EN 1993-1-8 2005) and $M_{B \text {, }}$ $k$,mes of the W2-1 connection depending on the number of bolt rows.

presented. For each of these cases, moment resistance was calculated also using the component method (EN 1993-1-8 2005).

It is seen that only connections with one or two bolt rows below beam tensioned flange can be calculated by code (EN 1993-1-8 2005) without essential errors. It has been shown that the component method according to code (EN 1993-1-8 2005) does not provide a safe assessment of the load capacity of joints with a failure mode of 2 or 3 , with the number of internal bolt rows greater than 2 .

Two methods are proposed to improve the component method.

Modified Component Method (MCM) introduces a numerical correction of the design resistance of the T-stubs in bolt rows 1 and 3, determined according to (EN 1993-1-8 2005) by formula (3), and a linear reduction of forces in further rows.

$$
F_{T, i}=\omega_{i} F_{T, i, R d}
$$

where: $F_{T, i, R d}$ - design resistance of T-stub in bolt row $i$, according to EN 1993-1-8/8.3.4, $\omega_{i}-$ coefficient reducing the bearing capacity of the T-stub in bolt row $i$, depending on the failure model 2 or 3 , according to Table 2 .

The load capacity of bolt rows $i>3$, is linearly reduced, in relation to the reduced load capacity of bolt row 3 , according to the formula (4):

$$
F_{T, i>3}=F_{T, 3 A} \frac{h_{i}-\beta h_{0}}{h_{3}-\beta h_{0}}
$$

where $\beta=0,5$ - for failure mode 3 , when $\max h_{i}>0.5 h_{0}, \beta=1 / 3$ - in other cases, $h_{0}$ - the height of the beam.

The second proposal is the Stiffness and Rotation Method (SRM), which assumes the distribution of internal forces in the bolts depending on the stiffness of the seating and the distance from the axis of the compression chord, in relation to the design resistance of the most loaded bolt rows determined according to (EN 1993-1-8). The capacities of individual bolt rows at the level of a given row are determined depending on the position in relation to the tension flange and the direction of force distribution. 
Table 2. Reduction coefficient $\omega_{i}$.

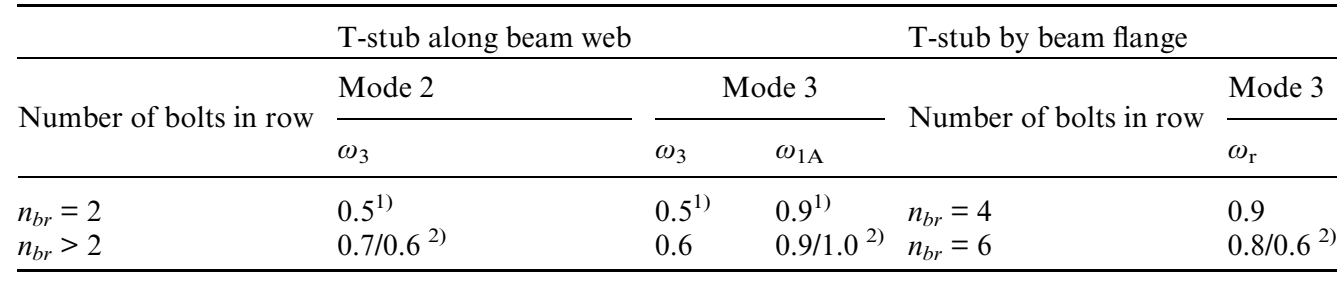

1) not applied when number of internal bolt rows $<3$

2) extended/flush end-plate

\section{ROBUSTNESS OF STEEL FRAMED STRUCTURES BY JOINTS DUCTILITY}

Each framed structures should be designed in two design situation: persistent, typical for the exploitation phase of structure life, and accidental, when the structure is subjected to unexpected loading, not included in everyday design. In a persistent situation (Figure 7a) loading acting on the frame is transferred through the entire system of appropriately connected columns and beam, while in accidental situations (Figure 7b), the column removal scenario may take place as a result of an explosion in the building, fire or impact of the vehicle. The accidental actions that should be taken into account are collected in (EN 1991-1-7 2006). Redistribution of forces in the internal connection took place: in the persistent situation (Figure 8a), the column is mainly subjected to the axial compression force; beams and joints are subjected to bending moment and shear forces. In an accidental situation (Figure 8b), when the column ceases to be support for the beams, large axial forces appear in the beams, and a sign of moment acting on joints change. The ability of a structure to withstand these events without being damaged to an extent disproportionate to the original cause is called robustness.

One of the strategies proposed by codes and regulations e.g. (DSA 2003), (DoD 2005), (EN 1991-1-7 2006), research projects (Robust structures by joint ductility 2009) is incorporating sufficient redundancy in the structure to facilitate the transfer of actions to alternative load paths following an accidental event. The main goal in the robustness design is shaping structures in such a way as to be able to create a secondary mechanism, i.e. catenary action in the scenario of column loss. The essential role of joints in providing catenary action and structural robustness is undisputed. Joints should possess not only essential load capacity to moments having a changeable sign but also very large rotation capacity to enable load redistribution.

a)

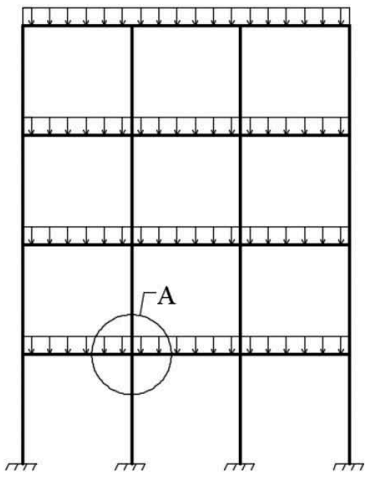

b)

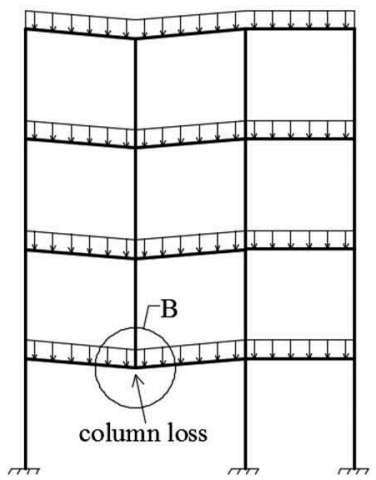

Figure 7. Design situations of frame structures: a) persistent situation, b) accidental situacion. 
The aim of the research project conducted in Rzeszow University of Technology was to:

- check the ability of very often used bolted end-plate joints for development of the catenary action, Flush and expended joints were considered,

- estimation of available rotation capacity of investigated joints, by experimental tests (Kukla \& Kozlowski 2019), and advanced FEA conducted on validated models of joints,

- recognizing failure modes of joints and find the way to change them to ductile mode, by the proposal of modification of joints,

- finding values of tie forces that appear in the structure during an accidental situation.

The project was conducted in the following stages:

a) Experimental tests of selected flush and extended bolted end-plate joints, conducted for isolated joints. Tests were conducted in cruciform set-up, for joints collected in Table 3.

Test stand of P-6 specimen and column web deflection are shown in Figure 9.

The set of obtained $M-\varnothing$ curves is presented in Figure 10 .

Based on the conducted tests, it can be concluded that:

- amongst the end-plate bolted connections with flush end-plate and extended end-plate, the highest bending resistance was obtained in connection with plate $15 \mathrm{~mm}$ (specimen P-5),

a)

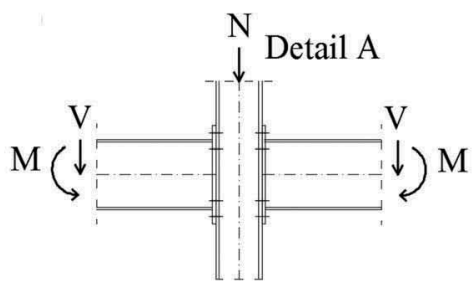

b)

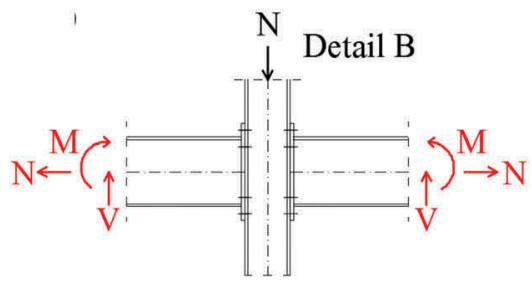

Figure 8. Configuration of force in connection: a) at the persistent situation, b) at the accidental situation of column loss.

a)

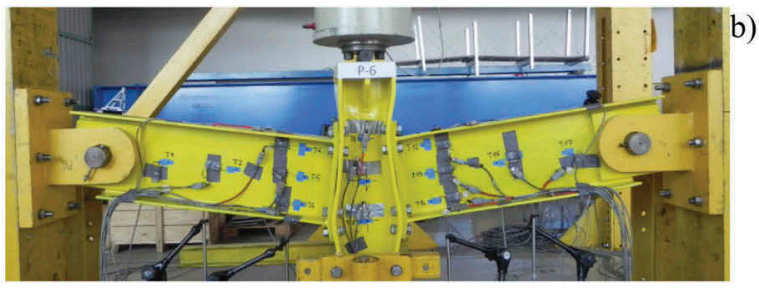

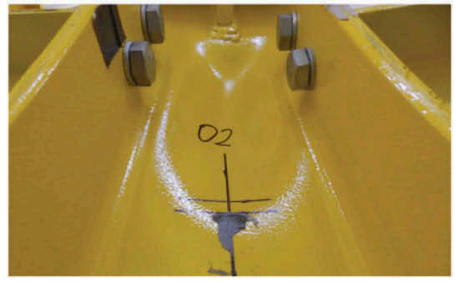

Figure 9. Sample P-6: a) view of test set-up, b) deflection of column web.

Table 3. Geometric parameters of tested specimens.

\begin{tabular}{lllllll}
\hline Specimen & Beam section & Column section & End plate & Platethickness [mm] & Bolt size & Bolt rows \\
\hline P-1 & IPE 300 & HEB 200 & Flush & 10 & M20 & 2 \\
P-2 & IPE 300 & HEB 200 & Flush & 15 & M20 & 2 \\
P-3 & IPE 300 & HEB 200 & Flush & 20 & M20 & 2 \\
P-4 & IPE 300 & HEB 200 & Extended & 10 & M20 & 4 \\
P-5 & IPE 300 & HEB 200 & Extended & 15 & M20 & 4 \\
P-6 & IPE 300 & HEB 200 & Extended & 20 & M20 & 4 \\
\hline
\end{tabular}


- end-plate joints with an extended plate (EP) show a greater capacity to develop catenary action than connections with flush plate - stronger tensile zone (4 tension bolts) was the main reason,

- the use of thicker endplates increases the bending capacity and the development of catenary action for unstiffened columns,

- the lack of stiffeners of the column web allows large deformations of the flanges and the web of the column, contributing to the increase in the rotation of connections significantly,

- results of connection tests were also used to validate numerical models of connections (Figure 11).

b) Recognizing behavior of joints tested in substructure, by advanced FEA of previously tested subframe (Kozlowski et al. 2011).Subframe analysis results are presented in details in (Kukla \& Kozlowski 2021).

c) Numerical parametric study of flush and extended end-plate steel joints in the case of column loss were conducted using validated FEM models. The effects of geometrical and mechanical features such as bolt size and grade, number of bolt rows, and end-plate thickness on joint behavior were examined.

The following conclusions can be drawn from the parametric study:

- the application of thin end plates (i.e., $6 \mathrm{~mm}$ and $8 \mathrm{~mm}$ ) decreases the deformability of the joint, and as a result, the rotational capacity,

- thick end plates are recommended in the case of an unstiffened column. A higher ultimate rotation and a developed catenary action are observed,

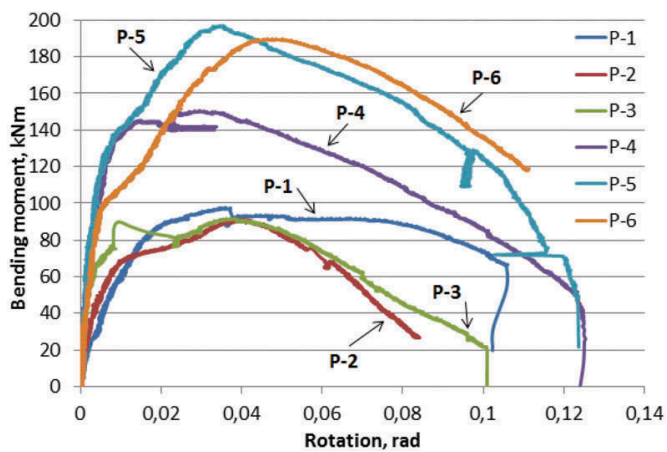

Figure 10. Comparison of the behavior of tested joints.

a)

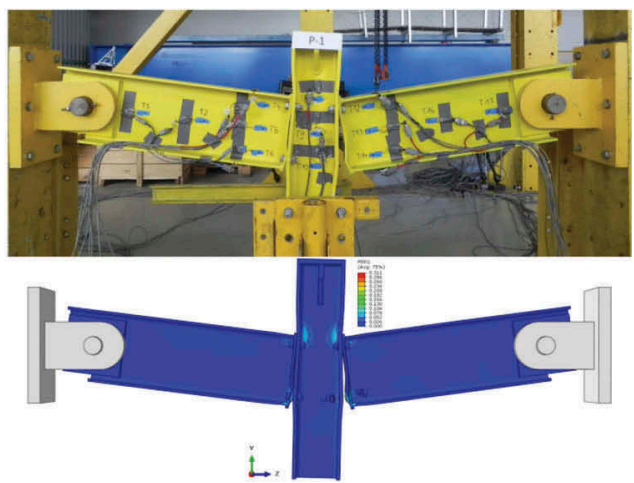

b)
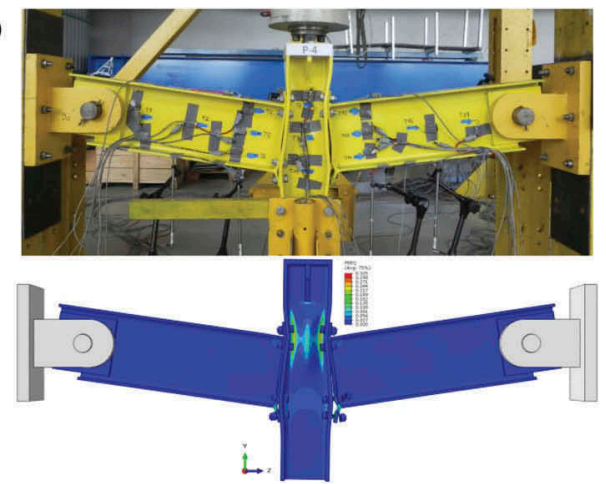

Figure 11. Comparison of experimental and numerical test of joint: a) $10 \mathrm{~mm}$ flush end plate, b) $10 \mathrm{~mm}$ extended end plate. 
- the higher bolt grade, i.e., class 12.9, and application of a larger bolt diameter has a positive influence on the ultimate joint behavior - leads to a significant increase in ultimate capacity and leads to avoiding the brittle failure mode of the joint. Therefore, the use of the M24 (or M27) bolt size is recommended.

a) Proposals of end-plate joint modifications.

Three innovative modifications of extended end-plate joints: additional channels, additional saddles, and additional rings were suggested to reach a significant raise in load and rotational capacities (Figure 12). Results of their numerical analysis and comparison of behavior are presented in Figure 13.

It is seen that proposed innovative modifications of extended end-plate joints lead to achieving a significant increase in stiffness, as well as load and rotational capacities. Additional elements used to improve the joints allow avoiding brittle damage to the bolts and create a ductile mechanism with significant development of catenary action.

a) Frame dynamic analysis in a sudden column loss scenario.

These analyses were conducted to estimate:

- required rotation capacity of joints to be able to achieve catenary action,

- behavior and failure modes of joint in destroyed frames.

a)

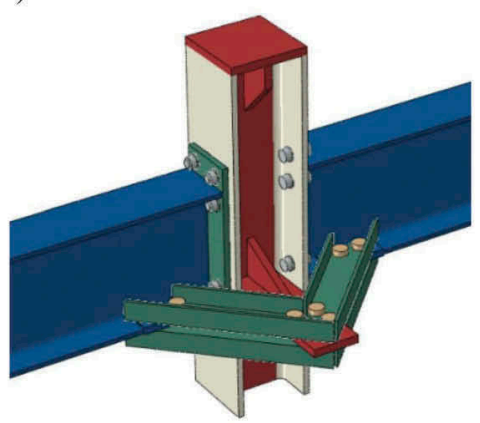

b)

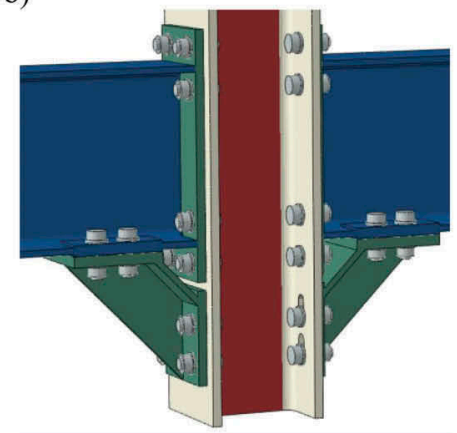

c)

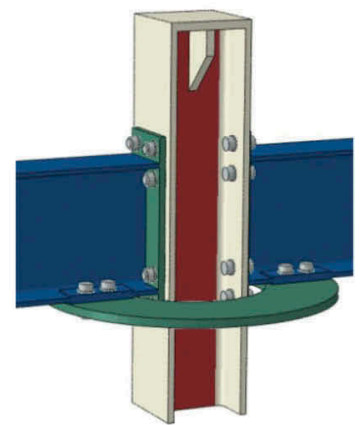

Figure 12. Proposal of joint modification by additional a) channel (AC), b) saddle (AS), c) ring (AR).

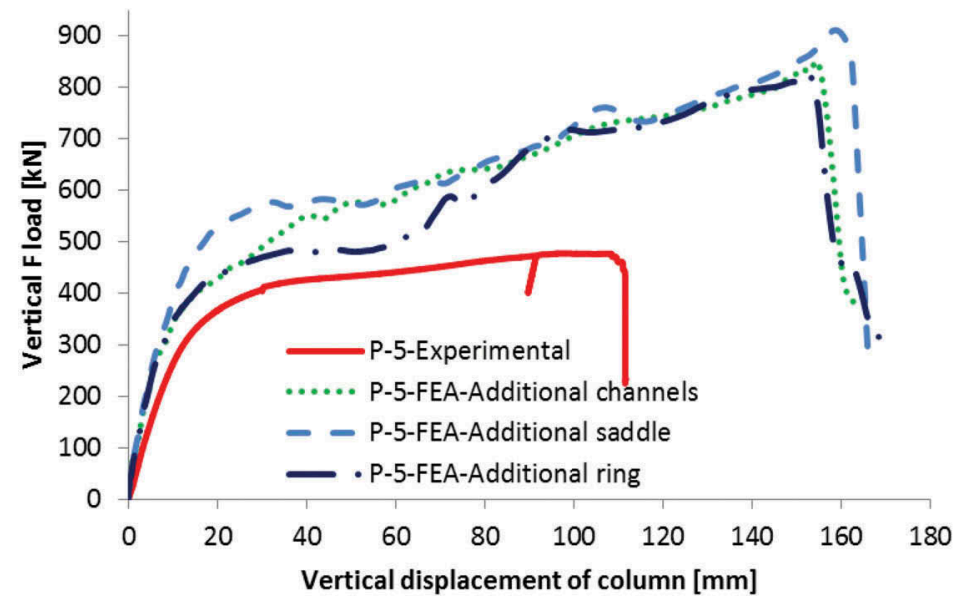

Figure 13. Effect of the modifications of joint with extended end plate. 
Few plane frames configuration were analyzed. Selected results for one of the analyzed frames (Figure 14) were presented below.

The full advanced MES models with solid elements for joints parts and shell elements for beams and columns were created and dynamically analyzed. End-plate joints as a connection of beam-to-column were applied to the whole frame. Two different cases of column loss in the analysis were adopted i.e. sudden, as for impact and/or blast, and gradual as in case of fire. Removal of a column was simulated as the loss of restraint in the support, for the central column at the "0" level (Figure 14).

The behavior of the frame under the sudden column loss scenario was presented in Figure 15. Bolted end-plate joints with $10 \mathrm{~mm}$ flush end-plate (Figure 15a) and $10 \mathrm{~mm}$ extended end-plate were used (Figure 15b). The extended end-plate joints allow for higher redistribution of load on beam length, which is visible by bent beams near the central column.

In Figure 16a the external W7 joint is shown at the end of the structure loading stage. A significant deflection of the column and endplate, as well as significant strains at column web at joint zone, can be observed. The W8 joint (Figure 16b) was destroyed by the fracture of all bolts of the lower rows.

Based on the obtained first results, the following remarks can be drawn:

- the application of end-plate bolted joint in frame structure leads to obtain a significant load capacity, rotational capacity, and large deformation of the joint and whole structure,

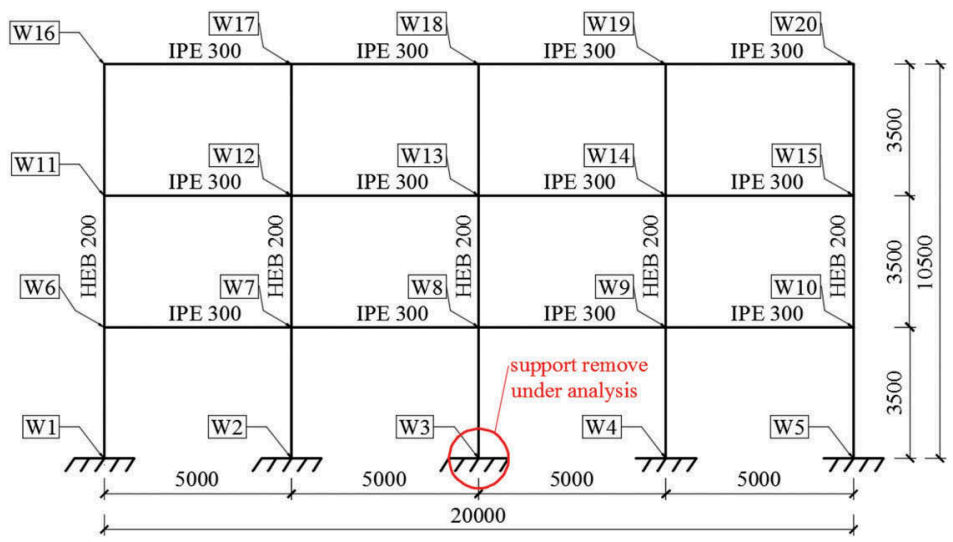

Figure 14. Static diagram of the analyzed frame.

a)

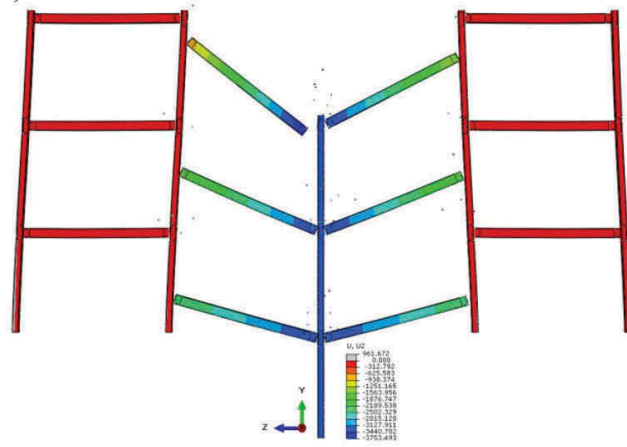

b)

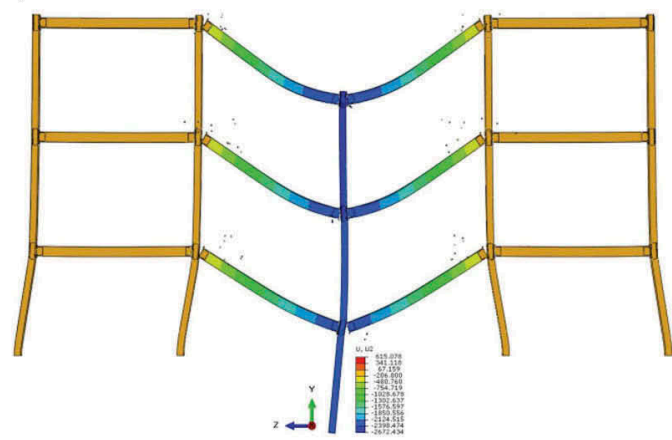

Figure 15. Map of vertical displacement of the frame under sudden column loss with a) $10 \mathrm{~mm}$ flush end plate joints, b) $10 \mathrm{~mm}$ extended end-plate joints. 
a)

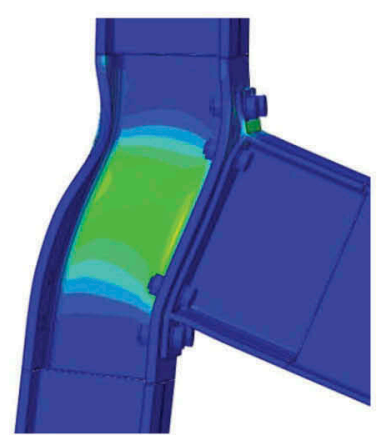

b)

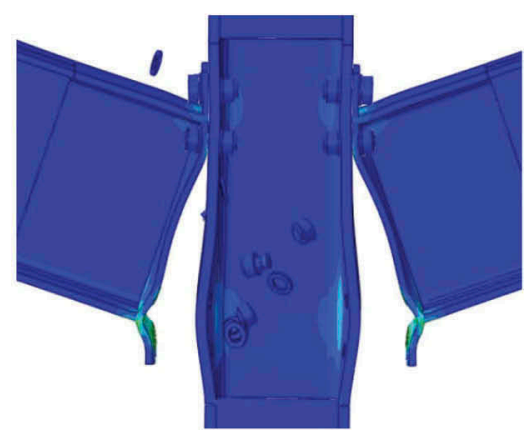

Figure 16. The failure mode of joint with $10 \mathrm{~mm}$ extended end-plate: a) external W7, b) internal W8.

- extended end plate joints has a higher load and rotational capacity, which is necessary for the development of catenary action in frame,

- the advanced model allows to observe all joint components behavior under time analysis, point out the weakest components and failure modes of joint and structure.

\section{ROTATION CAPACITY OF JOINTS}

Rotation capacity plays a very important role in an advanced analysis of steel frames, especially in the plastic design of structures and also in robustness analysis of steel frames. The previous analysis of rotation capacity was carried out with the use of the component method (Kuhlmann \& Fürch 1997), (da Silva \& Girao 2001), (Beg et al. 2004) probabilistic analysis (Beg \& Zupancic 2004), (da Silva 2004) and finite element method (Ostrowski 2014) but without practical guidelines how to use them in the design. The design procedures given in (EN 1993-1-8 2005) allow to estimate the main flexibility characteristics, as moment resistance $M_{j, R d}$ and initial stiffness $S_{j, \text { ini }}$ of the bolted and welded joints (Figure 17). As for rotation capacity, there is not enough information on how to calculate $\varnothing_{c u}$. There are only qualitative descriptions of the rotation capacity of selected connection types.

Rotation capacity is influenced by many variables, as the grade of steel, type and geometry of the joints(configuration, bolts arrangement, methods of joint stiffening), the section of beams and columns, joint placement (external or internal joint).

A large number of factors influencing rotation capacity forced researchers to find a simple, alternative to the component method, design procedure. One of them is based on the theory of experimental design and fine element analysis.

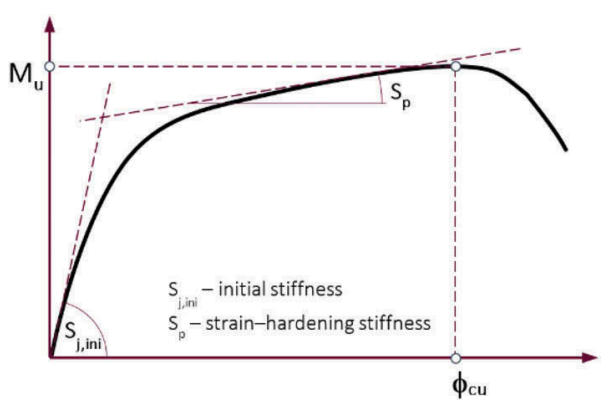

Figure 17. Graphical representation of rotation capacity. 


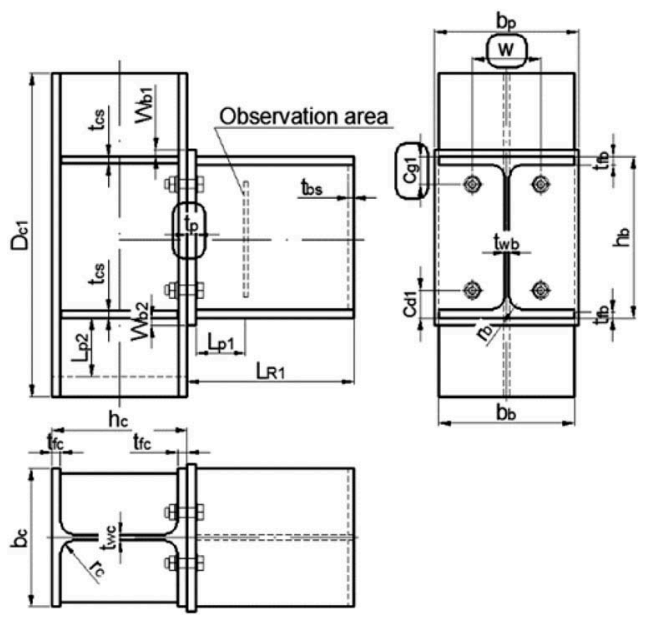

Figure 18. View of investigated join and designation of variable factors: , $t_{p},,, c_{g l}$, and ,w”.

Theory of experimental design (Polanski 1984), (Kozlowski \& Ostrowski 2019) gives researchers a very effective and efficient tool to analyses multi-factors processes in technology and science. It allows to a remarkable reduction of needed experiments and/or numerical simulations, which must be conducted to obtain an analytical model of the investigated object.

Theory of experimental design was adopted to the numerical simulation by FEM and used to obtain rotation capacity of selected, e.g. stiffened flush end-plate steel joint shown in Figure 18.

The following procedure was used to obtain the rotation capacity:

- hierarchical validation of FEM models (Figure 19) was performed by comparing the results obtained from the experimental tests with the results of FEM models (Ostrowski \& Kozlowski 2015),

- after parametric study the factor showing the strongest influence on the rotation of the joint were selected, i.e. thickness of the end-plate $t_{p}$, horizontal bolt spacing $w$, distance from the bolt axis to the upper edge $c_{g l}$ (Figure 18),

- on the basis of the substantive analysis of the most frequently used in practice solutions, the range of variability of the tested factors was determined as:

$t_{p}=10 \div 20 \mathrm{~mm}, w=120 \div 180 \mathrm{~mm}, c_{g 1}=50 \div 90 \mathrm{~mm}$,

- constant factors have been established as beam section HEA 360, column section HEB 300, S235 steel grade, M20 bolts, class 10.9,

- in order to determine the function of the maximum rotation angle of the joint, the theory of experimental design [9] adapted to numerical simulations was used. Hartley's PS/S, PS/DSP: Ha3 (Table 4), based on the hyper sphere (hK) with 11 variable factor systems was chosen,

- using a validated FEM model, calculations of joints with dimensions resulting from the experiment plan were made, in order to obtain a rotation angle $\varnothing_{c u}$ (Figure 17).

Solving all configurations of the experiment's plan allowed elaborating the response surface of the rotation angle. Results of this analysis are presented in Figure 20.

The function of rotation capacity angle was assumed as a polynomial function as below:

$$
\varphi_{c u}=t_{p}^{\alpha} \cdot c_{g 1}^{\beta} \cdot w^{\gamma}-A
$$

where: $a, b, g$ - are the coefficients of polynomial, A - is the constant of the polynomial.

The coefficients of polynomial described by the equation (5) were calculated by the program Statistica 12, with the use of the nonlinear regression analysis. The following function of available rotation capacity of joint was obtained: 
a)

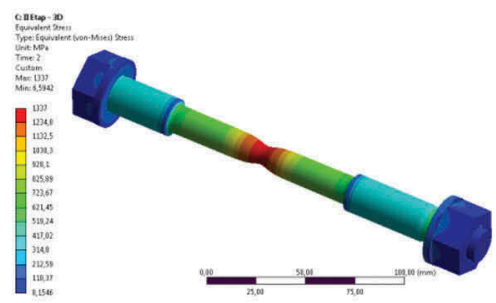

c)

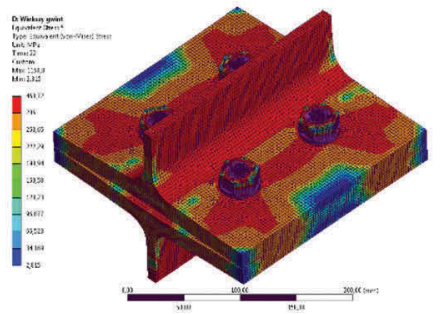

b)

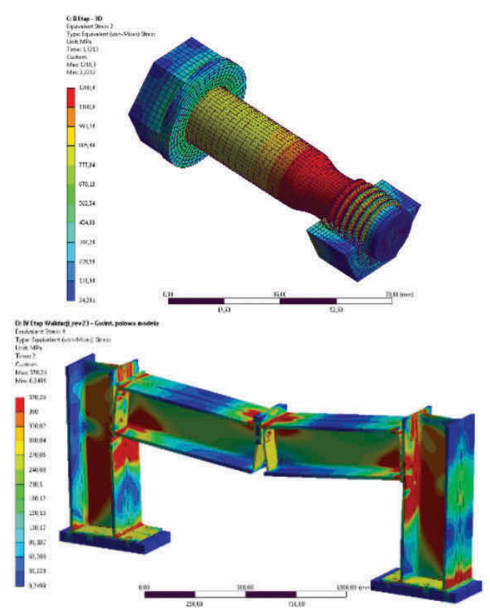

Figure 19. Stages of hierarchical validation: a) Stage I - tension test of a steel sample, b) Stage II - tension of a bolt in a bolt-washer-nut set, c) Stage III - tension of T-stubs, d) Stage IV - bending of the beam-to-column joint in the subframe.

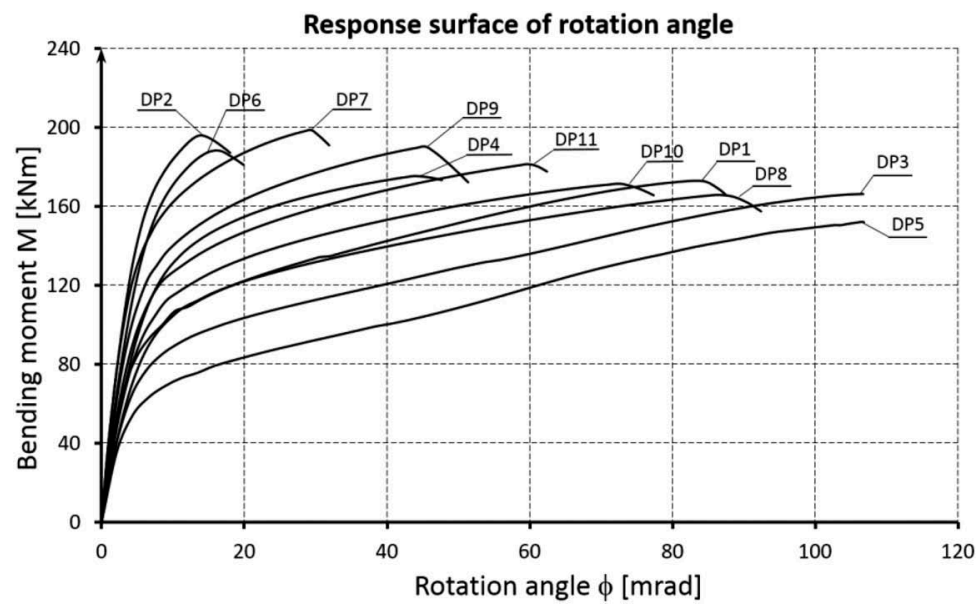

Figure 20. Moment-rotation of joints analyzed in experiment plan.

$$
\varphi_{c u}=t_{p}^{-1,267} \cdot c_{g 1}^{1,044} \cdot w^{0,714}-42,48
$$

Such procedures can be used to analyze other joint configurations. Finally, a catalog of joints with values of available rotation capacity will be created and can be used in the design.

\section{CONCLUSIONS}

Unique experimental tests of four beam splices of beam $1000 \mathrm{~mm}$ and $1500 \mathrm{~mm}$ high were performed. Results of tests, especially values of forces in particular bolt rows and also results of the parametric study conducted by FEA using validated models of high beam splices lead to conclusions that: 
Table 4. Experimental plan Hartley's PS/S.

\begin{tabular}{llllllll}
\hline & \multicolumn{1}{c}{$\mathrm{x}_{\mathrm{k}}$} & \multicolumn{2}{c}{$x_{k}$} & Rotation [mrad] \\
\cline { 2 - 7 } & $\mathrm{x}_{1}$ & $\mathrm{x}_{1}$ & $\mathrm{x}_{2}$ & $\mathrm{t}_{\mathrm{p}}$ & $\mathrm{c}_{\mathrm{g} 1}$ & $\mathrm{w}$ & $\emptyset_{\mathrm{cu}}$ \\
\hline 1 & -1 & -1 & 1 & 12.11 & 58.45 & 167.32 & 83.07 \\
2 & 1 & -1 & -1 & 17.89 & 58.45 & 132.68 & 13.98 \\
3 & -1 & 1 & -1 & 12.11 & 81.55 & 132.68 & 106.69 \\
4 & 1 & 1 & 1 & 17.89 & 81.55 & 167.32 & 43.75 \\
5 & -1.732 & 0 & 0 & 10.00 & 70.00 & 150.00 & 106.84 \\
6 & 1.732 & 0 & 0 & 20.00 & 70.00 & 150.00 & 15.85 \\
7 & 0 & -1.732 & 0 & 15.00 & 50.00 & 150.00 & 29.38 \\
8 & 0 & 1.732 & 0 & 15.00 & 90.00 & 150.00 & 86.58 \\
9 & 0 & 0 & -1.732 & 15.00 & 70.00 & 120.00 & 45.37 \\
10 & 0 & 0 & 1.732 & 15.00 & 70.00 & 180.00 & 72.59 \\
11 & 0 & 0 & 0 & 15.00 & 70.00 & 150.00 & 59.81 \\
\hline
\end{tabular}

- distribution of forces in the particular bolt rows is not equal on the beam height. Also the moment resistance of the joint $M_{j, R k}$ determined by component method acc. to code (EN 1993-1-8 2005) is much bigger than reached during experimental tests,

- only connections with one or two bolt rows below tension beam flange can be calculated by code (EN 1993-1-8 2005) without essential errors,

- the component method does not provide a safe assessment of the load capacity of joints with a failure mode 2 or 3 , with the number of internal bolt rows greater than 2 .

Two methods are proposed to improve the component method to be safe also for joints applied in very high beams with multi bolt rows.

Experimental tests of joints advanced FEA of isolated joints, the subframe and whole steel frames, as well as wide parametric study, lead to the conclusion that:

- application of end-plate bolted joint in frame structure leads to obtain a significant load capacity, stiffness, and large deformation of the joint and whole structure,

- use of thin end plates (i.e., $6 \mathrm{~mm}$ and $8 \mathrm{~mm}$ ) decreases the deformability of the joint, and as a result, the rotational capacity,

- extended end plate joints, compared to flush, has a higher load and rotational capacity, which is necessary for the development of catenary action in frame,

- application of a larger bolt diameter has a positive influence on the ultimate joint behavior - leads to a significant increase in ultimate capacity and leads to avoiding the brittle failure mode of the joint. Therefore, the use of the M24 or M27 bolt size is recommended.

Three innovative modifications of extended end-plate joints: additional channels, additional saddles, and additional rings were suggested to reach a significant raise in load and rotational capacities.

The theory of experimental design was adopted for numerical simulation by FEM and used to obtain the available rotation capacity of the exemplary joint. i.e. stiffened flush end-plate. By application of the proposed procedure, a catalogue of most often used in practice joints, with values of available rotation capacity can be created and be used as a design tool in steel frame design.

\section{REFERENCES}

Beg, D. \& Zupancic, E. 2004. Statistical evaluation of rotation capacity of moment connections. Connections in Steel Structures $V$. Amsterdam.

Beg, D. \& Zupancic, E. \& Vayas, I. 2004. On the rotation capacity of moment connections. Journal of Constructional Steel Research 60:601-620.

Borgsmiller, J. \& Sumner, E. \& Murray, T. 1995. Tests of Extended Moment End-Plate Connections Having Large Inner Pitch Distances, in Research Report CE/VPI-ST-95/01. Department of Civil Engineering. Virginia Polytechnic Institute and State University. Blacksburg VA. 
Department of Defence (DoD), Unified facilities criteria (UFC): Design of structures to resist progressive collapse, Washington, 2005.

EN 1991-1-7: Actions on structures - Part 1-7: General actions - Accidental actions. CEN. 2006.

EN 1993-1-8: 2005. Design of steel structures. Part 1-8 Design of joints. CEN. 2005.

General Services Administration (GSA). 2003. Progressive collapse analysis and design guidelines for a new federal office buildings and major modernization project.

Jain, N. 2015. Developing and validating new bolted end-plate moment connection configurations. Virginia Tech.

Katula, L. 2007. Bolted end-plate joints for crane brackets and beam-to-beam connections, in PhD. Dissertation. University of Technology and Economics Budapest.

Kawecki, P. \& Kozlowski, A. 2020. Experimental investigation of end-plate splices multiple bolt rows of large girders. Journal of Constructional Steel Research, Volume 167:1-19.

Kawecki, P. 2020. Ultimate limit states of multi bolts end-plate splices of the welded I girders. PhD Dissertation. Rzeszow University of Technology.

Kozlowski, A. \& Gizejowski, M. \& Sleczka, L. \& Pisarek, Z. \& Saleh, B. 2011. Experimental investigation of the joints behaviour-Robustness assessment of steel and steel concrete composite frames. Proceeding of the 6th European Conference on Steel and Composite Structures: 339-344. Budapest.

Kozłowski, A. \& Ostrowski, K. 2019. Application of theory of experimental design and FEA to assessment of rotation capacity of steel joints. Advances in Resource-saving Technologies and materials in Civil and Environmental Engineering. Cham:Springer:188-194.

Kuhlmann, U. \& Fürch, A. 1997. Rotation Capacity of Steel Joints. COST Project C1 Meeting.

Kukla, D. \& Kozlowski, A. 2021. Parametric study of steel flush and extended end-plate joints under column loss scenario. Engineering Structures 2021 (Paper under review).

Kozlowski, A. \& Kukla, D. 2019. Experimental tests of steel unstiffened double side joints with flush and extended end plate. Archives of Civil Engineering. vol. LXV. ISSUE 4:127-154.

Kukla, D. \& Kozlowski, A. 2021. Analysis of steel bolted end-plate joints under accidental situation. ICMS 2021. Poznan, 2021. (Paper under review).

Morrison, S. \& Astaneh-Asl, A. \& Murray, T. 1986. Analytical and Experimental Investigation of the Multiple Row Extended Moment End-Plate Connection with Eight Bolts at the Beam Tension Flange. University of Oklahoma Norman OK Research Report FSEL/MBMA 84-04 Fears Structural Engineering Laboratory.

Ostrowski, K. 2014. Finite element analysis of the rotation capacity of beam-to-column end-plate bolted joints. Eurosteel 2014. September 10-12. Naples.

Ostrowski, K. \& Kozlowski, A. 2015. Hierarchical validation of FEM models. XIV International Scientific Conference Rzeszow - Lwow - Koszyce. Rzeszow.

Polanski, Z. 1984. Experimental design in technique. (In Polish). PWN. Warsaw.

Robust structures by joint ductility. 2019. Research Found of Coal and Steel.

Ryan, J.1999. Evaluation of Extended End-Plate Moment Connections Under Seismic Loading. Master of Science Civil Engineering Thesis. Virginia Polytechnic Institute.

Silva, S. \& Borges, L. \& Garvasio, H. 2004. A probabilistic evaluation of the rotation capacity of endplate beam-to-column steel joints. Connections in Steel Structures V. Amsterdam.

Silva, S. \& Girao, A. 2001. A ductility model for steel connections. Journal of Constructional Steel Research 57: 45-70.

Sumner, E. 2003. Unified design of extended end-plate moment connections subject to cyclic loading. Dissertation submitted to the Faculty of the Virginia Polytechnic Institute. 